\title{
Regerach Article: Constraints in adoption of integrated pest management practices by cotton growers in Nimar region of Madhya Pradesh
}

— NEERJA PATEL, MANISH KUMAR, NISHITH GUPTA AND ANKITA PANDEY

Article Chronicle:

Received :

08.06.2017;

Revised :

12.07.2017;

Accepted :

24.07.2017

KeY Words: Integrated pest management, Sustainability, Intercropping, Constraints

Author for correspondence :

NEERJA PATEL

Krishi Vigyan Kendra

(R.V.S.K.V.V.), DEWAS (M.P.) INDIA

See end of the article for authors' affiliations
SUMMARY : Integrated Pest Management (IPM) is a pest management system that in the context of the associated environment and the population dynamics of the pest species, utilizes all suitable techniques and methods in as compatible manner as possible and maintain the pest population at level below these causing economic injury. This approach has been globally accepted for achieving sustainability in agriculture and maintaining the agro-eco-system. Cotton being a major commercial crop of the Nimar region in Madhya Pradesh and keeping in view the importance of IPM to manage the insects and pests of cotton crop, the present study was carried out to assess the present status of adoption of IPM practices by cotton growers in Barwani district of Nimar region. The multistage sampling technique was employed to select 140 respondents from seven blocks of the district for present study. The perusal of data indicated that the majority of respondents adopted recommended chemical control measure (95.33\%). The great majority of the farmers are using chemicals to protect their cotton crop along with other cultural practices like grazing by sheep and goat in cotton field after last picking (79.16\%), use of certified seed (85.66\%) and use of recommended dose of fertilizers (66.33\%). The findings also indicated that the majority of cotton growers faced problems that inadequacy of labours and high wage rate for undertaking the manual work like handpicking $(87.85 \%)$, adoption of biological control measures and mechanical control (82.14\%). The lack of knowledge about yellow sticky traps for control of white fly (74.28\%), lack of knowledge about use of pheromone trap (82.14\%), lack of knowledge about intercropping of cotton with cowpea/maize/lady finger as trap crop (73.57\%), lack of knowledge about use of bio-agent $(58.57 \%$ ) and lack of knowledge about procedure of preparing extract of neem seed kernel $(52.14 \%)$ were the major constraints in adoption of IPM programme.

How to cite this article : Patel, Neerja, Kumar, Manish, Gupta, Nishith and Pandey, Ankita (2017). Constraints in adoption of integrated pest management practices by cotton growers in Nimar region of Madhya Pradesh. Agric. Update, 12(3): 487-490; DOI : 10.15740/HAS/AU/12.3/487-490. 